\section{$\mathrm{AJ} H$}

Received : 16.11 .2015

Revised : 01.05 .2016

Accepted : 10.05.2016

\title{
Genetic variation for morphological and physico- chemical traits in jamun (Syzygium Cuminii Skeels)
}

\section{Y. SOMI SINGH, VIVELA D. SHIRA ${ }^{1}$ AND G.S.K. SWAMY ${ }^{2}$}

ABSTRACT : Among 23 genotypes studied, maximum fruit weight (15.67 g), fruit diameter (2.68 $\mathrm{cm})$ and pulp weight (11.83 $\mathrm{g}$ ) were recorded in the genotype KJS-300. The genotype KJS-18 recorded significantly longest fruit $(3.90 \mathrm{~cm})$, while the shortest $(2.05 \mathrm{~cm})$ was recorded in genotype KJS-43. The highest pulp content $(80.64 \%)$ was recorded in genotype KJS-25. The maximum pulp to seed ratio (6.17) was recorded in KJS-02 and lowest seed weight (1.17 g) was recorded in genotype KJS-24. Highest TSS $(21.23 \%)$ and acidity $(0.66 \%)$ was recorded in genotype KJS-03 and KJS-25, respectively. Significantly maximum TSS to acid ratio (73.75) was recorded in genotype KJS-300. Highest anthocyanin (1.36 OD) and ascorbic acid $(28.17 \mathrm{mg} / 100$ g) was recorded in KJS-18 and KJS-02, respectively. Highest total sugar (16.37\%) and nonreducing sugar $(16.36 \%)$ were registered in the genotype KJS-09. Maximum sugar to acid ratio (53.24) and reducing sugar $(0.030 \%)$ was recorded in the genotype KJS-26 and KJS-43 respectively.

KEY WORDS : Jamun genotypes, Variations, Physical and chemical parameters

Author for correspondence : Y. SOMI SINGH

Bidhan Chandra Krishi

Viswavidyalaya, Mohanpur, NADIA

(W.B.) INDIA

Email : somifrt@ rediffmail.com
HOW TO CITE THIS ARTICLE : Singh, Y. Somi, Shira, Vivela D. and Swamy, G.S.K. (2016). Genetic variation for morphological and physico-chemical traits in jamun (Syzygium Cuminii Skeels). Asian J. Hort., 11(1) : 163-167, DOI : 10.15740/HAS/TAJH/11.1/163-167. 